Effect of flow and volume-oriented incentive spirometer exercise on the hemodynamic parameters in cardiac surgery patients: Pilot interventional study

Pranjal Keny ${ }^{* 1}$, Rajani Pagare ${ }^{2}$.

${ }^{* 1}$ Student BPT, Deccan Education Society's Brijlal Jindal college of Physiotherapy, Pune, India.

2 Professor and HOD (Cardiovascular and Respiratory Physiotherapy), Deccan Education Society's Brijlal Jindal college of Physiotherapy, Pune, India.

\title{
ABSTRACT
}

Background: The 2 types of incentive spirometers (flow and volume-oriented) prescribed after cardiac surgery demonstrate a difference in the pattern of breathing, diaphragm mobility, pulmonary function test. Limited research is available on effect of incentive spirometer on hemodynamic parameters.

Purpose: To provide hemodynamic perspective for preference of a specific type of incentive spirometer after cardiac surgery.

Method: Ideal method of performing breathing on their prescribed incentive spirometer was explained. On $2^{\text {nd }}$ day post surgery, heart rate, respiratory rate, oxygen saturation and blood pressure were noted immediately before and after performing 8 breaths on incentive spirometer.

Results: The intergroup comparison i.e., difference between changes caused by flow and volume-oriented incentive spirometers are statistically insignificant. The intra group comparison, the changes in hemodynamic parameters by flow and volume-oriented incentive spirometers are statistically insignificant, except for heart rate with flow-oriented incentive spirometers showed statistically significant increase. Conclusions: There is no difference in the impact of flow oriented and volume-oriented Incentive spirometers on hemodynamic parameters in post cardiac surgery patients.

KEY WORDS: Incentive spirometer, Cardiac surgery, Heart rate, Blood pressure, Respiratory Rate, Oxygen saturation.

Address for correspondence: Pranjal Keny, 3/185, Raj Mahal, Rd 28-A, Near Municipal school, Sion (East), Mumbai, Maharashtra, India. Pin Code- 400 022. E-Mail: kenypranjal@gmail.com

Access this Article online

Quick Response code

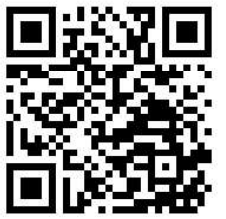

DOI: $10.16965 /$ ijpr.2021.126

\section{Journal Information}

International Journal of Physiotherapy and Research

ISSN (E) 2321-1822 | ISSN (P) 2321-8975

https://www.ijmhr.org/ijpr.html

DOI-Prefix: https://dx.doi.org/10.16965/ijpr

\section{Article Information}

Received: 29 Mar 2021

Peer Review: 30 Mar 2021

Revised: None
Accepted: 21 May 2021

Published (O): 11 Jun 2021

Published (P): 11 Jun 2021

\section{INTRODUCTION}

The annual count of cardiac surgeries in India has increased from 10,000 in mid 1990 to about 60,000 by the year 2010 [1]. Owing to sedentary lifestyle, stress, smoking, diabetes, unhealthy diet this count has only increased [2]. Post operative complications endanger healthy recovery. To prevent this, use of various prophylactic and therapeutic respiratory techniques have been encouraged. One of the strongly recommended technique by most healthcare professionals is the use of Incentive spirometer [3]. Incentive spirometer is a hand held medical device, used to provide visual biofeedback based on the depth of inspiration, to promote slow, prolonged inhalation, mimicking the natural mode of breathing. This helps in reducing pleural pressure thereby improving lung expansion along with gaseous exchange. This ultimately targets 
prevention/ reduction or reverse in postoperative atelectasis [4-6]. There are 2 types of incentive spirometers widely used-flow oriented and volume oriented. The floworiented incentive spirometer has three small partially closed cylinders connected in series with 1 ball in each, these cylinders, calibrated as $300 \mathrm{cc} / \mathrm{sec}, 600 \mathrm{cc} / \mathrm{sec}, 900 \mathrm{cc} / \mathrm{sec}$ respectively are connected to a pipe connecting to a mouth piece. When air is inhaled through the mouthpiece the flow-oriented incentive spirometer projects feedback by uplifting the ball based on the speed of the air inhaled. The volumeoriented incentive spirometer also has a pipe connecting a mouthpiece to a single cylinder but with calibration levels as $500 \mathrm{ml}, 600 \mathrm{ml}$ up to $1500 \mathrm{ml}$ thus the amount of air inhaled will cause the disc to rise [7]. Due to this difference in the principle of biofeedback in the 2 types of incentive spirometers, it is observed clinically that the breathing pattern is different with each of them. The available literature compares the 2 types of incentive spirometers based on respiratory Parameters like Pulmonary Function Test findings, diaphragm mobility, etc in different populations $[5,6]$. No comparison between the 2 types of incentive spirometers is done based on hemodynamic parameters in post operative patients. This becomes critical in case of post operative cardiac surgery patients as there is altered cardiac autonomic regulation [9-15]. Aim of the study is To compare variation in hemodynamic parameters caused by use of flow and volume orientated incentive spirometers in cardiac surgery patients.

\section{METHODS}

Design of study: Interventional comparative study.

Inclusion criteria: Patients of both genders, stable post cardiac surgery patients (surgery through median sternotomy only), patients introduced to spirometer after surgery.

Exclusion criteria: Rhythm abnormalities, pacemakers, uncontrolled hypertension, pre-existing respiratory co-morbidities, ongoing Ca channel blockers and Beta blockers. Materials used were, Paper and pen,
ICU monitor, Incentive spirometer (flow-oriented and volume-oriented according to the type prescribed to the patient).

Procedure: 28 patients post cardiac surgery were randomly assigned to use flow-oriented incentive spirometer or volume-oriented incentive spirometer. On $1^{\text {st }}$ day post-surgery, Explanation was given on how to ideally perform incentive spirometer breathing on their own prescribed spirometer. On $2^{\text {nd }}$ day post-surgery, from ICU monitor values for heart rate, respiratory rate, oxygen saturation and blood pressure were noted before and immediately after performing 8 breaths on incentive spirometer. Instructions for use of incentive spirometer- Incentive spirometer was given with the patient was positioned in lying $\left(45^{\circ}\right)$ with a pillow under the knees. The patient is instructed to hold the spirometer in an upright position, exhale normally, and then place the lips tightly around the mouthpiece. The next step is a slow inhalation to raise the ball (flow-oriented) or the piston/ plate (volume-oriented) in the chamber. Maximum inhalation, followed by a breath-hold and normal exhalation. The patient was instructed to take a deep sustained breath with a breath holding for 2-3 seconds. Then the patient was instructed to breathe out slowly and passively [16].

Data analysis: 2 Groups were formed based on the type of incentive spirometer used after cardiac surgery i.e. flow oriented and volume oriented. Equal gender distribution was ensured in both groups. 28 patients' hemodynamic parameters were assessed before and immediately after using incentive spirometer for Breathing exercise and the changes were noted and compared. All statistical analysis was performed on Graph pad Prism version 8.4.0 software. P-value of $<0.01$ with confidence interval of $95 \%$ was considered statistically significant. Statistical tests used were paired test and unpaired t test for data of heart rate, respiratory rate, blood pressure. Wilcoxon rank sum test and Mann-Whitney tests were used for data of oxygen saturation.

\section{RESULTS AND DISCUSSION}

In this pilot study, total 28 post operative patients of cardiac surgery through median 
sternotomy were included, 14 patients using flow oriented incentive spirometry and 14 using volume oriented incentive spirometer. Equal gender distribution was ensured in both groups. Age group included in the study was 18-75 years. The parameters of heart rate, respiratory rate, oxygen saturation, systolic blood pressure and diastolic blood pressure were evaluated for any effect due to use of flow-oriented incentive spirometer exercise. The same process was done to find effect of volume-oriented incentive spirometer exercise. Lastly, these two changes were compared. The results are summarized in the table. The $p$ value for heart rate with the use of flow-oriented incentive spirometer exercise is statistically significant. All other $p$ values do not satisfy the condition $p$ value $<0.01$. Effect of flow-oriented incentive spirometer exercise on respiratory rate, oxygen saturation, systolic blood pressure and diastolic blood pressure are not statistically significant. Effect of volume-oriented incentive spirometer exercise on heart rate, respiratory rate, oxygen saturation, systolic blood pressure and diastolic blood pressure are not statistically significant. The difference in the effect of flow and volume-oriented incentive spirometer exercise on heart rate, respiratory rate, incentive spirometer, oxygen saturation, systolic blood pressure and diastolic blood pressure are not statistically significant.

This study was organized to find the effect of flow and volume-oriented incentive spirometer exercise on hemodynamic parameter on patients who had undergone cardiac surgery through median sternotomy. 28 patients were divided into 2 groups based on the type of incentive spirometer prescribed to them (flow or volume) with males and females equally distributed in the 2 groups. On the $2^{\text {nd }}$ post operative day, changes in heart rate, respiratory rate, oxygen saturation, systolic blood pressure and diastolic blood pressure were observed immediately before and after the exercise with the patients' prescribed incentive spirometer. Very few studies till today have linked hemodynamic parameters to the use of incentive spirometers. Through this study, it is found that flow-oriented incentive spirometer exercise shows statistically significant change on HR.
The effect of flow-oriented incentive spirometer exercise on respiratory rate, oxygen saturation, systolic blood pressure and diastolic blood pressure are not statistically significant. Effect of volume-oriented incentive spirometer exercise on heart rate, respiratory rate, incentive spirometer, oxygen saturation, systolic blood pressure and diastolic blood pressure are not statistically significant. The difference in the effect of flow and volume-oriented incentive spirometer exercise on heart rate, respiratory rate, incentive spirometer, oxygen saturation, systolic blood pressure and diastolic blood pressure are not statistically significant. There is statistically significant increase in the heart rate that is caused by use of flow-oriented incentive spirometer. This is supported by study done in 2001 by Josef Weindler, Ralph-Thomas Kiefer [9]; to find efficacy of post operative incentive spirometer if it is influenced by device specific imposed work of breathing. 30 postoperative cardiac surgery patients were grouped according to risk (air entry).

Each group was given a set of each volume and flow-oriented incentive spirometer session then examined for inspiratory capacity, maximal inspiratory pressure and work of breathing imposed. This concluded that flow orientated incentive spirometer imposes twice the amount of load on breathing than volume orientated incentive spirometer. Besides this another study done in 2014, Adriana Lunardi, Desiderio Parras, Renata [10] performed a study to find the effect of volume orientated incentive spirometer and flow orientated incentive spirometer on chest wall volume, inspiratory muscle activity and thoracicabdominal asynchrony was seen in healthy elders compared to healthy adults.

16 subjects of each adult and elderly population were given a session of randomized sequence of flow and volume orientated spirometers, they found a) thoracic-abdominal asynchrony was in adults with flow only where as in elderly by both flow and volume. b) Flow spirometer increased muscle activity in elderly 
Table 1: Mean, standard deviation, $p$-value for effect on heart rate with flow and volume-oriented incentive spirometers.

\begin{tabular}{ccccccc}
\hline & \multicolumn{2}{c}{ Flow } & \multicolumn{2}{c}{ Volume } & Flow & Volume \\
\cline { 2 - 7 } & Pre & Post & Pre & Post & Difference & Difference \\
\hline Mean & 94.93 & 98 & 91.71 & 93.78 & 3.07 & 2.07 \\
SD & 12.71 & 13.1 & 13.66 & 13.03 & 4.14 & 5.43 \\
P Value & \multicolumn{2}{c}{0.01} & \multicolumn{2}{c}{0.1769} & \multicolumn{2}{c}{0.5883} \\
\hline
\end{tabular}

Table 2: Mean, standard deviation, p-value for effect on respiratory rate with flow and volume-oriented incentive spirometers.

\begin{tabular}{ccccccc}
\hline & \multicolumn{2}{c}{ Flow } & \multicolumn{2}{c}{ Volume } & Flow & Volume \\
\cline { 2 - 7 } & Pre & Post & Pre & Post & Difference & Difference \\
\hline Mean & 25.36 & 26.36 & 22.93 & 22.5 & 1 & -0.43 \\
SD & 6.57 & 6.11 & 5.43 & 6.02 & 5.67 & 8.32 \\
P Value & \multicolumn{2}{c}{0.4371} & \multicolumn{2}{c}{0.8501} & \multicolumn{2}{c}{0.5569} \\
\hline
\end{tabular}

Table 3: Mean, standard deviation, $p$-value for effect on oxygen saturation with flow and volume-oriented incentive spirometers.

\begin{tabular}{ccccccc}
\hline & \multicolumn{2}{c}{ Flow } & \multicolumn{2}{c}{ Volume } & Flow & Volume \\
\cline { 2 - 8 } & Pre & Post & Pre & Post & Difference & Difference \\
\hline Mean & 97.36 & 95.93 & 98.5 & 97.93 & -1.43 & -0.22 \\
SD & 2.56 & 3.29 & 2.31 & 2.97 & 2.76 & 1.05 \\
P Value & \multicolumn{2}{c}{0.125} & \multicolumn{2}{c}{0.2188} & \multicolumn{2}{c}{0.1271} \\
\hline
\end{tabular}

Table 4: Mean, standard deviation, $p$-value foe effect on systolic blood pressure with flow and volume-oriented incentive spirometers.

\begin{tabular}{|c|c|c|c|c|c|c|}
\hline & \multicolumn{2}{|c|}{ Flow } & \multicolumn{2}{|c|}{ Volume } & \multirow{2}{*}{$\begin{array}{c}\text { Flow } \\
\text { Difference }\end{array}$} & \multirow{2}{*}{$\begin{array}{c}\text { Volume } \\
\text { Difference }\end{array}$} \\
\hline & Pre & Post & Pre & Post & & \\
\hline Mean & 116.14 & 116.64 & 113.21 & 115.43 & 0.5 & 2.21 \\
\hline SD & 18.94 & 16.35 & 20.44 & 24.72 & 9.32 & 8.84 \\
\hline P Value & \multicolumn{2}{|c|}{0.844} & \multicolumn{2}{|c|}{0.3658} & \multicolumn{2}{|c|}{0.6218} \\
\hline
\end{tabular}

Table 5: Mean, standard deviation, p-value for effect on diastolic blood pressure with flow and volume-oriented incentive spirometers.

\begin{tabular}{ccccccc}
\hline & \multicolumn{2}{c}{ Flow } & \multicolumn{2}{c}{ Volume } & Flow & Volume \\
\cline { 2 - 7 } & Pre & Post & Pre & Post & Difference & Difference \\
\hline Mean & 69.57 & 67.57 & 73.28 & 73.71 & -2 & 0.43 \\
SD & 9.76 & 10.92 & 13.3 & 15.03 & 3.46 & 4.41 \\
P Value & \multicolumn{2}{c}{0.05} & \multicolumn{2}{c}{0.7223} & \multicolumn{2}{c}{0.1175} \\
\hline
\end{tabular}

more than in adults. c) Inspiratory flow in both surgery. In a stable pateinet, Post Coronary groups with both spirometer remains same. Artery Bypass Grafting surgery this target heart d) Inspiratory time was increased with volume spirometer in adults whereas no change in elderly. This implies that use of flow-oriented incentive spirometers requires more effort demanding more oxygen supply to the muscles in return causing the heart rate to increase and meet the demand. However, the mean heart rate pre and post the incentive spirometer exercise using the flow type, are $94.93 \pm 12.71$ and $98 \pm 13.1$ which means the maximal difference obtained could be of 17 beats which lies within the range of target heart rate. The target heart rate is the range for post exercise heart rate, calculated after rate in phase 1 cardiac rehabilitation is (basal heart rate + 30) [8].

Clinically, though flow orientated incentive spirometer imposes twice the amount of load on breathing than volume orientated incentive spirometer there is no significant hemodynamic changes seen by the use of it in Post-operative cardiac patients. Therefore, both type of incentive spirometer can be prescribed safely. Limitation of the study was that the volume of air inhaled was not considered.

\section{CONCLUSION}

There is no difference in effect of flow orien 
tated and volume orientated incentive spirometer on hemodynamic parameters in cardiac surgery patients.

\section{ACKNOWLEDGEMENTS}

We thank Kalyani Savant, Shrinidhi Kulkarni, Simran Sane, Saniya Pradhan at the Deccan Education Society's Brijlal Jindal college of Physiotherapy, Pune, India for their help extended towards this study and lastly all participants for their kind support towards this study.

\section{Conflicts of interest: None}

\section{REFERENCES}

[1]. Upendra Kaul \& Vineet Bhatia. Perspective on coronary interventions \& cardiac surgeries in India. Indian J Med Res, 2010; 132(suppl 5):543-548.

[2]. Prabhakaran D, Jeemon P, Roy A. Cardiovascular Diseases in India: Current Epidemiology and Future Directions. Circulation, 2016; 133(Suppl 16):160520.

[3]. Adam E M Eltorai, Grayson L Baird, Ashley Szabo Eltorai, et al. Perspectives on Incentive Spirometry Utility and Patient Protocols. Respiratory Care, 2018; 63 (Suppl 5):519-531.

[4]. Wilkins RL, Stoller JK, Kacmarek RM. Lung expansion therapy. In Egan's fundamentals of respiratory care, 9th edition. St. Louis: Mosby Elsevier; 2009:903-920.

[5]. Gopala Krishna Alaparthi, Alfred Joseph Augustine, Anand R, Ajith Mahale. Comparison of flow and volume-oriented incentive spirometry on lung function and diaphragm movement after laparoscopic abdominal surgery: a randomized clinical pilot trial. International Journal of Physiotherapy and Research, Int J Physiother Res, 2013; 1 (Suppl 5):274-78.

[6]. Denise de Moraes Paisani, Cibele Cristine Berto Marques Da Silva, Adriana Claudia Lunardi, et al. Comparison of incentive spirometers on thoracoabdominal mechanics and inspiratory muscular activation in morbidly obese. European Respiratory Journal, 2012; 40:1183.

[7]. Cairo JM. Mosby's respiratory care equipment. Elsevier: Health Sciences; 2013.
[8]. Jennifer L. Reed, Angelica Z. Blais, Marja-Leena Keast, et al. Performance of Fixed Heart Rate Increment Targets of 20 vs 30 Beats per Minute for Exercise Rehabilitation Prescription in Outpatients with Heart Failure. Clinical research, 2017; 33 (Suppl 6):777-784.

[9]. Josef Weindler, Ralph-Thomas Kiefer. The Efficacy of Postoperative Incentive Spirometry Is Influenced by the Device Specific Imposed Work of Breathing. CHEST 2001; 119:1858-1864.

[10]. Adriana Lunardi, Desiderio Parras, Renata, Denise Paisani, Cibele Marques, Clarice Tanaka, Celso Carvalho. Effect of volume orientated versus flow orientated incentive spirometry on chest wall volume, inspiratory muscle activity and thoracic-abdominal synchrony in elderly. Respiratory Care 2014; 59(Suppl 3):420-426.

[11]. Charles Weissman, MD. Pulmonary Complications After Cardiac Surgery. Seminars in Cardiothoracic and Vascular Anesthesia, 2004; 8 (Suppl 3):185211.

[12]. Kathy Stiller, Joseph Montarello, Malcolm Wallace, Meredith Dajf, Ruth Grant, Sue Jenkins, Bob Hall, Helen Yates. Efficacy of breathing and coughing exercises in the prevention of pulmonary complications after coronary artery surgery. Chest,1994; 105 (Suppl 3):741-747.

[13]. V. F. Parriera, G.M. Tornich, RR Britto, R.F Sampaio. Assessment of tidal volume and thoracic-abdominal motion using volume and flow orientated spirometers in healthy subjects. Brazil J Med Biol Res. 2005; 38(Suppl 7):1105-12.

[14]. Nenad Lakusic, Darija Mahovic, Peter Kruzliak, et al. Changes in Heart Rate Variability after Coronary Artery Bypass Grafting and Clinical Importance of These Findings. BioMed research international 2015; 10:1155-7

[15]. Bauernschmitt R, et al. Impairment of cardiovascular autonomic control in patients early after cardiac surgery. Eur J Cardiothoracic Surg 2004; 25(Suppl 3):320-6.

[15]. Ruben Restrepo, Richard Wettstein, Leo Wittnebel, Michael Tracy. Incentive spirometry:2011. Respi Care 2011; 56(Suppl 10):1600-1604.
How to cite this article:
Pranjal Keny, Rajani Pagare. Effect of flow and volume-oriented incentive
spirometer exercise on the hemodynamic parameters in cardiac surgery
patients. Pilot interventional study. Int J Physiother Res 2021;9(3):3843-
3847. DOI: $10.16965 /$ ijpr.2021.126 